\title{
Quantification of Nitroimidazoles Residues in Swine Liver by Liquid Chromatography-Mass Spectrometry with Atmospheric Pressure Chemical Ionization
}

\author{
Hai Wang · Zijian Wang · SuYing Liu • \\ Yanbing Jiang · Yinliang Wu $\cdot$ Jihao Shan
}

Received: 21 December 2007 / Accepted: 9 October 2008/Published online: 25 October 2008

(C) Springer Science+Business Media, LLC 2008

\begin{abstract}
A liquid chromatography-mass spectrometry method was developed for the simultaneous determination of ronidazole (RNZ), metronidazole (MNZ) and dimetridazole (DMZ) residues in swine liver. Following liquidliquid extraction, the HLB solid-phase extraction was used for further purification. The targets were detected by atmospheric pressure chemical ionization (APCI) following the reverse phase liquid chromatography separation. Consequently, the detection limits for the method were $0.5 \mu \mathrm{g} / \mathrm{kg}$ for MNZ, $1.0 \mu \mathrm{g} / \mathrm{kg}$ for RNZ and $0.5 \mu \mathrm{g} / \mathrm{kg}$ for DMZ, respectively. The accuracies were determined using swine liver samples fortified at levels of $0.5,1,2$, and $4 \mu \mathrm{g} /$ $\mathrm{kg}$ and the mean recoveries of the analytes were between $66 \%$ and $81 \%$.
\end{abstract}

Keywords Nitroimidazoles $\cdot$ LC-APCI-MS $\cdot$ Swine liver

Ronidazole (1-methyl-2-[(carbamoyloxy)methyl]-5-nitroimidazole, RNZ), Dimetridazole (1,2-dimethyl-5-nitroimidazole, DMZ), Metronidazole (1-(2-hydroxyethyl)-2-methyl-5nitroimidazole, MNZ) were used for the treatment and prevention of haemorrhagic enteritis in pigs and certain

H. Wang $\cdot$ Z. Wang

State Key Laboratory of Environmental Aquatic Chemistry,

Research Center for Eco-Environmental Sciences,

Chinese Academy of Science, Shuangqing Street,

Haidian District, Beijing 100085, People's Republic of China

H. Wang $(\varangle) \cdot$ S. Liu $\cdot$ Y. Jiang $\cdot$ Y. Wu $\cdot$ J. Shan Quality Control and Inspection Center for Animal Products, Ministry of Agriculture, China Animal Disease Control Center, Maizidian Street, Chaoyang District, Beijing 100026,

People's Republic of China

e-mail: cadc2008@126.com bacterial and protozoal diseases in poultry. For their potentially harmful effects on human health (IARC 1987), nitroimidazoles have been banned from use in food producing animals within the European Union (Council Regulation (EEC) No. 2377/90, 1990), the U.S. (Animal Medicinal Drug Use Clarification Act 1994) and China (Regulation No. 193, 2002). The structures of RNZ, DMZ and MNZ are shown in Fig. 1.

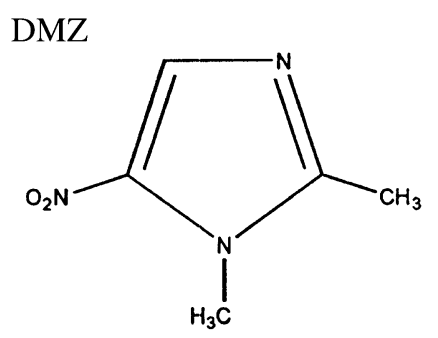

MNZ
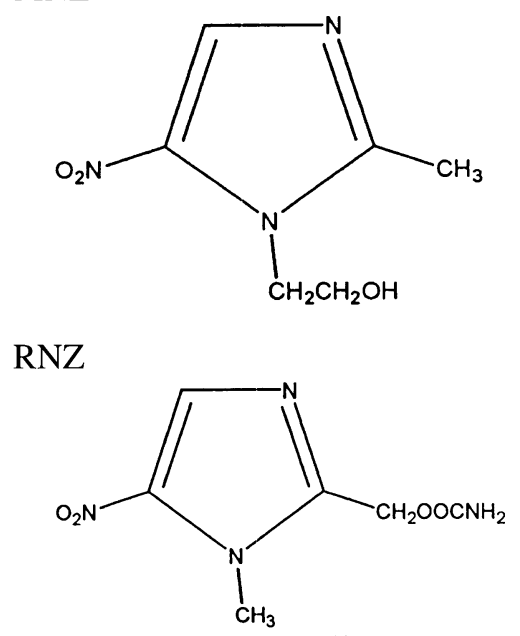

Fig. 1 Molecular structures of RNZ, DMZ and MNZ 
ELISA screening test for nitroimidazoles in egg and chicken muscle (Anne-Catherine et al. 2005) and GC-MS method for detection of nitroimidazoles in turkey and swine muscle have been described (Polzer and Gowik 2001). LC-MS method for determination of nitroimidazole in poultry meat have also been reported (Dominique et al. 2000). Liver is the recommended target matrix for the residue control of nitromidazoles in pig. However, determination of nitromidazoles residues in liver was more complicate than muscle or egg due to the biological complexity of liver. Employing gas chromatography-mass spectrometry (GC-MS) for analysis of nitromidazoles required derivatization prior to detection, which would introduce more uncertainty. LC-MS should be superior to GC-MS in residual analysis of these compounds for its high selectivity, sensitivity and no need for derivatization. In this study, a determination method for multi-residues in swine liver was described using liquid chromatography coupled to atmospheric pressure chemical ionization mass spectrometry (LC-APCI-MS). The method has been validated according to the Commission Decision 2002/657/EC. The results showed that it appropriate for monitoring illegal use of selected banned compounds in livestock production.
Table 1 Ions monitored for each compound with their cone voltage

\begin{tabular}{llcl}
\hline Compound & Ions monitored in SIM & $M / Z$ & Cone voltage(V) \\
\hline Ronidazole & {$[\mathrm{M}+\mathrm{H}]^{+}$} & 201 & 18 \\
& {$\left[\mathrm{M}+\mathrm{H}-\mathrm{NH}_{2} \mathrm{CO}_{2}\right]^{+}$} & 140 & 40 \\
Dimetridazole & {$[\mathrm{M}+\mathrm{H}]^{+}$} & 142 & 34 \\
& {$\left[\mathrm{M}+\mathrm{H}-\mathrm{C}_{2} \mathrm{H}_{5} \mathrm{O}\right]^{+}$} & 96 & 45 \\
Metronidazole & {$[\mathrm{M}+\mathrm{H}]^{+}$} & 172 & 29 \\
& {$\left[\mathrm{M}+\mathrm{H}-\mathrm{CO}_{2}\right]^{+}$} & 128 & 37 \\
\hline
\end{tabular}

\section{Materials and Methods}

HPLC grade methanol, acetonitrile, ethyl acetate and hexane were from Merck (Darmstadt, Germany). Hydrochloric acid and ammonia were provided by Beijing Chemical Co. (Beijing, China). Water was purified using a Milli-Q Synthesis system from Millipore (Bedford, MA). The analytical standards RNZ, MNZ and DMZ were obtained from Sigma (St. Louis, MO). Oasis HLB (6 cc $500 \mathrm{mg}$ ) extraction columns were from Waters (Milford, MA).

The liquid chromatography-mass spectrometer system consisted of a Waters Alliance 2695 LC system equipped

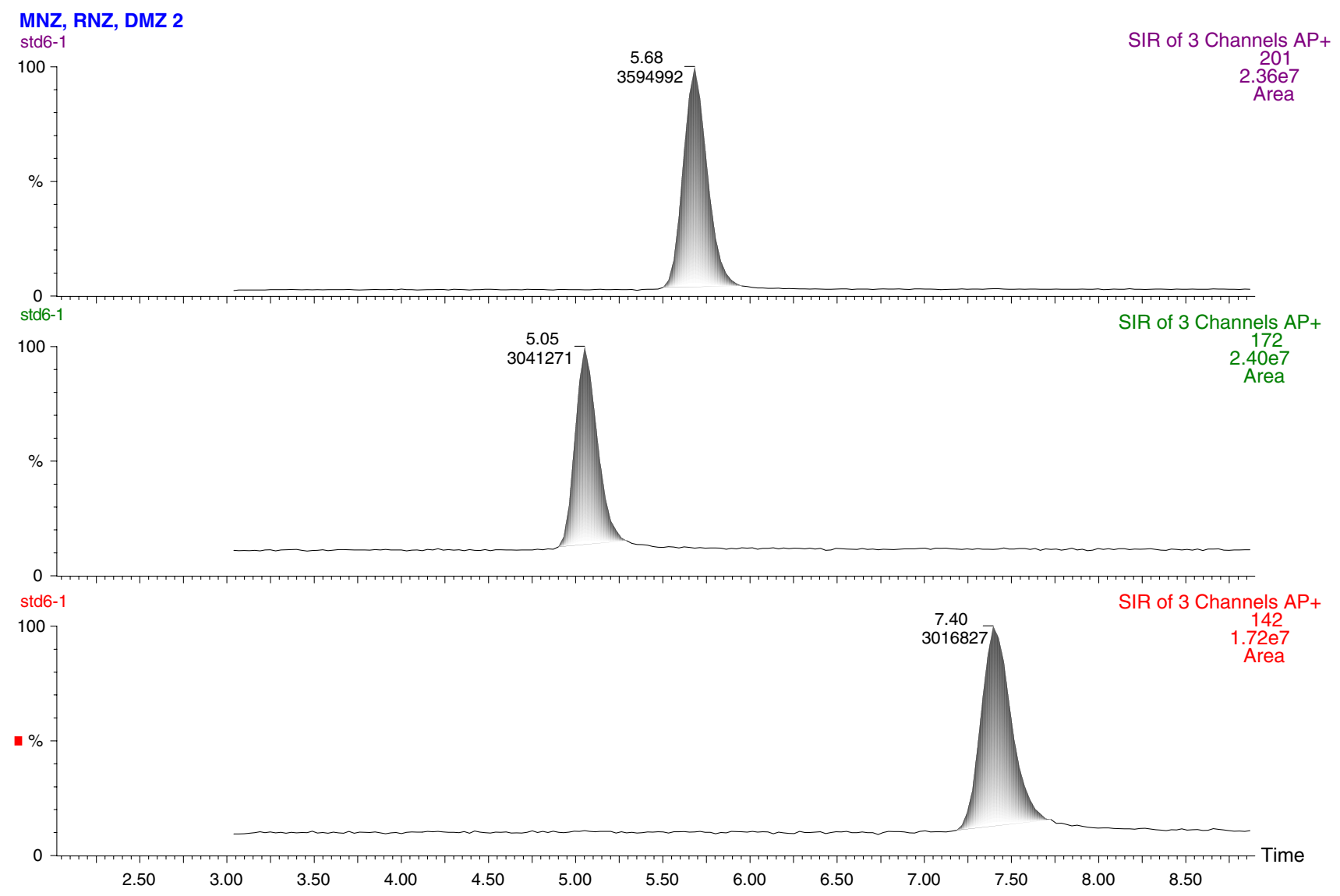

Fig. 2 LC-MS chromatograms of nitroimidazoles standards solution (RNZ, MNZ and DMZ) at $25.0 \mu \mathrm{g} / \mathrm{L}$ 
with a Micromass (Manchester, UK) ZQ4000 mass spectrometer. The source temperature was $100^{\circ} \mathrm{C}$, nitrogen was used as nebulization and desolvation gas, at flow-rates of 65 and $550 \mathrm{~L} / \mathrm{h}$, respectively. The ionization mode used was the positive APCI mode, with the corona pin discharge set at $3.5 \mathrm{kV}$. Dwell time delay were $0.1 \mathrm{~s}$.

For each analyte, the two most abundant product ions were monitored using the conditions given in Table 1. Chromatographic separation was achieved on a Symmetry C18 $(150 \mathrm{~mm} \times 4.6 \mathrm{~mm}$ i.d $5 \mu \mathrm{m})$ at a flow rate of $1.0 \mathrm{~mL} / \mathrm{min}$ the oven is maintained at $30^{\circ} \mathrm{C}$. The mobile phases used consisted of $0.01 \mathrm{~mol} / \mathrm{L}$ ammonium acetate solution consist of $9 \%$ acetonitrile.

About $10 \mathrm{~g}$ homogenized swine liver samples were added into $50 \mathrm{~mL}$ polypropylene centrifuge tubes, then $15 \mathrm{~mL}$ ethyl acetate were added. After vortexing $(2 \mathrm{~min})$ and centrifugation $(3000 \times g, 5 \mathrm{~min})$, supernatant was collected. Repeated the extraction with $15 \mathrm{~mL}$ of ethyl acetate and combined with the first portion. The organic solutions were evaporated to near dryness with a rotary evaporator at $50^{\circ} \mathrm{C}$. The residue was dissolved in $4 \mathrm{~mL}$ $1 \mathrm{M} \mathrm{HCl}$ and $3 \mathrm{~mL}$ ethyl acetate. The mixture was decanted into a $100 \mathrm{~mL}$ separatory funnel containing $30 \mathrm{~mL}$ hexane, $4 \mathrm{~mL} 1 \mathrm{M} \mathrm{HCl}$ and $3 \mathrm{~mL}$ ethyl acetate were again added to the separatory funnel. This mixture was gently shaken for $60 \mathrm{~s}$ and equilibrate for $15 \mathrm{~min}$ the aqueous layer was collected in a $10 \mathrm{~mL}$ flask, then the $\mathrm{pH}$ was adjusted to $4.8-5.2$ with $1 \mathrm{M} \mathrm{HCl}$ or $5 \mathrm{M} \mathrm{NaOH}$.

HLB SPE column were previously conditioned with $10 \mathrm{~mL}$ methanol and $10 \mathrm{~mL}$ water, the extracts were added to the SPE columns, and these extracts were allowed to flow through by gravity. The columns were washed with $3 \mathrm{~mL}$ water then the nitroimidazoles were eluted with $3 \mathrm{~mL}$ methanol. The effluent was collected and evaporated to $0.5 \mathrm{~mL}$ under nitrogen gas. It was reconstituted to $1 \mathrm{~mL}$ with mobile phase, and $50 \mu \mathrm{L}$ solution was injected for analysis.

\section{Results and Discussions}

The SIM chromatograms of nitroimidazoles standards and spiked samples were shown in Figs. 2 and 3.

Linearity of the detector response was checked from a set of eight working standards ranging in concentration from 1.0 to $500 \mu \mathrm{g} / \mathrm{L}$. The curves were found to be linear

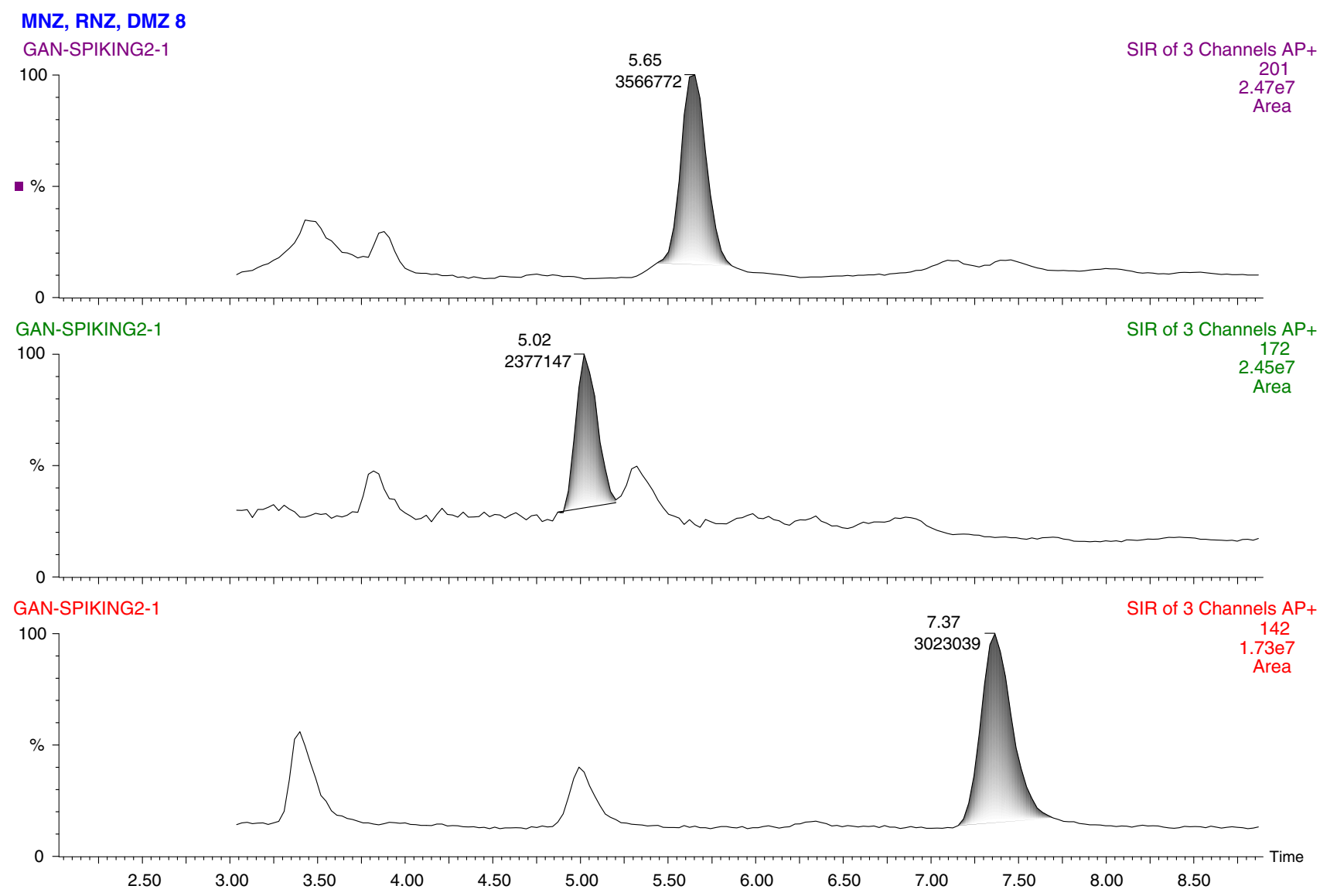

Fig. 3 LC-MS chromatograms of spiking swine liver sample containing nitroimidazoles (RNZ, MNZ and DMZ) fortified at $1.0 \mu \mathrm{g} / \mathrm{kg}$ 
Table 2 Inter-assay variation for the recovery of the analytes from swine liver

\begin{tabular}{llll}
\hline Analyte & Fortification level $\mu \mathrm{g} / \mathrm{kg}$ & Recovery $(\%)$ \\
\cline { 3 - 4 } & & Mean $\pm \mathrm{s}(\mathrm{n}=5)$ & $\mathrm{RSD}$ \\
\hline Ronidazole & 1 & $67 \pm 5.8$ & 8.6 \\
& 2 & $73 \pm 5.1$ & 7.0 \\
& 4 & $79 \pm 3.0$ & 3.8 \\
Dimetridazole & 0.5 & $68 \pm 5.0$ & 7.4 \\
& 1 & $71 \pm 4.3$ & 6.1 \\
Metronidazole & 0.5 & $81 \pm 3.9$ & 4.8 \\
& 1 & $68 \pm 4.2$ & 6.2 \\
& 2 & $66 \pm 4.0$ & 6.1 \\
& & $80 \pm 3.2$ & 4.0 \\
\hline
\end{tabular}

Table 3 Intra-assay variation for the recovery of the analytes from swine liver

\begin{tabular}{llll}
\hline Analyte & Fortification level $\mu \mathrm{g} / \mathrm{kg}$ & \multicolumn{2}{l}{ Recovery $(\%)$} \\
\cline { 3 - 4 } & & Mean $\pm \mathrm{s}(\mathrm{n}=5)$ & $\mathrm{RSD}$ \\
\hline Ronidazole & 1 & $70 \pm 6.5$ & 9.3 \\
& 2 & $73 \pm 6.2$ & 8.5 \\
& 5 & $80 \pm 5.0$ & 6.3 \\
Dimetridazole & 1 & $72 \pm 7.1$ & 9.9 \\
& 2 & $75 \pm 6.1$ & 8.1 \\
& 5 & $75 \pm 7.2$ & 7.2 \\
Metronidazole & 1 & $76 \pm 7.1$ & 9.6 \\
& 2 & $81 \pm 6.1$ & 9.3 \\
& 5 & & 7.5 \\
\hline
\end{tabular}

over this range $\left(r^{2}=0.999\right)$. The limits of detection were determined from representative blank samples. It was equal to three times of signal-to-noise. The limit of quantitation for the method was $0.5 \mu \mathrm{g} / \mathrm{kg}$ for MNZ, $1.0 \mu \mathrm{g} / \mathrm{kg}$ for RNZ and $0.5 \mu \mathrm{g} / \mathrm{kg}$ for DMZ, respectively. The accuracies and precision of the method were determined using swine liver samples fortified at levels of $0.5,1,2$, and $4 \mu \mathrm{g} / \mathrm{kg}$, respectively. Intra-assay variation was determined by analysing five samples within a single run, mean recoveries of the analytes were between $72 \%$ and $81 \%$. RSD were typically at $<8.6 \%$ (Table 2 ). Inter-assay variation was determined by analysing samples on five different occasions, to evaluate the run to run variation in the method. Mean recoveries of analytes were between $66 \%$ and $81 \%$ with RSD at $<9.9 \%$ (Table 3).

A method based on liquid chromatography coupled to atmospheric pressure chemical ionization mass spectrometry was described for identification of nitroimidazole residues in swine liver. The limit of quantitation for the method was $0.5 \mu \mathrm{g} / \mathrm{kg}$ for MNZ, $1.0 \mu \mathrm{g} / \mathrm{kg}$ for RNZ and $0.5 \mu \mathrm{g} / \mathrm{kg}$ for DMZ, respectively. The method described here has been validated according to the Commission Decision 2002/657/EC. The achieved confirmatory limits proved the efficiency of this methodology for control of trace levels of these substances.

Acknowledgments Funding supports from Natural Science Foundation of China (20621703) and the Foundation of Ministry of Science \& Technology of China (2002BA906A75) are gratefully acknowledged.

\section{References}

Animal Medicinal Drug Use Clarification Act (1994) U.S.

Anne-Catherine H, Leen M, Els D, Terrence F, Christopher E, Philippe D (2005) Development of an ELISA screening test for nitroimidazoles in egg and chicken muscle. Anal Chim Acta 534:157-162. doi:10.1016/j.aca.2004.06.037

Commission Decision (2002) 2002/657/EC, EC

Council Regulation no (1990) 2377/90, EC

Dominique H, Bernard D, Michel L (2000) Determination of four nitroimidazole residues in poultry meat by liquid chromatography-mass spectrometry. J Chromatogr A 882:89-98. doi: 10.1016/S0021-9673(00)00336-8

IARC (1987) Monographs on the evaluation of carcinogenic risks to humans. Overall evaluations of carcinogenicity. Supplement 7

Regulation No 193 (2002) Ministry of agriculture, P.R. China

Polzer J, Gowik P (2001) Validation of a method for the detection and confirmation of nitroimidazoles and corresponding hydroxy metabolites in turkey and swine muscle by means of gas chromatography-negative ion chemical ionization mass spectrometry. J Chromatogr B Biomed Sci Appl 761:47-60. doi: $10.1016 / \mathrm{S} 0378-4347(01) 00299-7$ 